\title{
VISIÓN CRÍTICA DE LAS TEORÍAS POSTRACIONALISTAS DE LA EDUCACIÓN
}

\author{
Leticia Barrios Graziani \\ Universidad Central de Venezuela
}

\section{INTRODUCCIÓN}

La tradición postmoderna se centra en una crítica demoledora de la modernidad y de sus cimientos: los metarelatos, las utopías, las leyes generales, la idea del progreso, todos ellos son sometidos a un amplio cuestionamiento. La postmodernidad reivindica la diversidad, lo individual, lo cotidiano, construyendo un paradígma opuesto a los valores modernos. En el campo educativo la postmodernidad se expresa en el postracionalismo, cuyo centro de atención será la superación de las anquilosadas verdades del modelo racional; la crítica a la visión autoritaria y represiva de la educación y a su carácter de simple transferencia, así como, a las estrecheces del pensamiento racional para abarcar otras esferas de la vida intelectual.

Sin embargo, las corrientes postracionalistas han resultado dilemáticas, muchas de ellas se desenvuelven acordes con el pensamiento neoliberal y con a sociedad del mercado, lo cual genera una distorsión en la formación y en los valores de los estudiantes. Los nudos críticos de las teorías postracionalistas se aprecian en primer lugar, en la excesiva importancia que le otorga a los aspectos intuitivos y emocionales, relegando el pensamiento racional a una situación despreciable, y en segundo lugar, al psicologismo extremo que conduce inevitablemente al desequilibrio entre el homo politicus y el homo psychologicus.

En este punto es importante aclarar la diferencia entre individuo y sujeto. Los sujetos son los individuos entendidos como nudos de relaciones sociales, productos a la vez que productores, creadores de esas relaciones sociales a la vez que objetos de la acción de esas fuerzas. Mientras que el individuo posee una condición inmediata y limitada a la esfera privada y orientada hacia la constante adaptación al entorno que lo rodea. Entre tanto, la subjetividad se refiere a la conciencia y a la capacidad de resistencia y cambio del individuo en un determinado momento histórico.

La importancia de reivindicar uno $u$ otro en el modelo educativo altera de manera determinante las subjetividades que de ella se pueden desprender. Si el énfasis se pone en el individuo es muy probable que la subjetividad sea la de una amplia domesticación y satisfacción con el entorno, pero sí el interés se centra en el sujeto, la subjetividad estará orientada a la autonomía, la crítica y la transformación. Son estos los puntos que interesa dilucidar en las presentes líneas.

\section{CRÍTICAS AL MODELO RACIONALISTA DE LA EDUCACIÓN}

Las teorías postracionalistas cuestionan las rigideces y estrecheces del pensamiento racional. Consideran que el modelo racionalista de la educación no toma en cuenta aquellas capacidades del intelecto humano que escapan de los límites de la lógica formal, tales como: la emocional, la intuitiva o la creativa. El procedimiento racionalista se limita a pasar de lo concreto a lo abstracto, de lo singular a lo general, sin tomar en cuenta la vida en su complejidad, la vida polisémica y plural que no se acomoda a las 
ideas generales y otras abstracciones estrechamente definidas. Tal como lo señala un representante de la postmodernidad, Maffesoli (1997):

"En su sentido más simple, el racionalismo separa lo que considera el bien o el mal, lo verdadero de lo falso, y olvida al mismo tiempo que la existencia es una constante participación mística, una correspondencia sin fin, en la que lo interior y lo exterior, lo visible y lo invisible, lo material y lo inmaterial entran a formar parte de una totalidad (..) El racionalismo olvida que, sí existe una ley, ésta es la coincidentia oppositorum, que hace que cosas, seres y fenómenos completamente opuestos puedan unirse. Al ignorar esto, el racionalismo se esfuerza por sofocar y excluir fragmentos enteros de la vida" (Maffesoli, 1997: 36)

Los postracionalistas también cuestionan la manía clasificatoria, encasilladora y etiquetadora del racionalismo, que da preferencias a las leyes generales, dominantes y separadas, a los conceptos estrictos y cerrados, todo lo cual lo convierte en un sistema de pensamiento totalmente desconectado de las fuerzas vivas de la sociedad, de la inventividad intelectual, de la originalidad y en fin, de la creación bajo todos sus aspectos.

Otro autor, Capra (1996) logra captar la esencia y las contradicciones del racionalismo occidental asociándolo con la tradición oriental del yin (pensamiento intuitivo) y el yang (pensamiento racional):

"El conocimiento intuitivo y el conocimiento racional son dos aspectos complementarios de la mente humana. El pensamiento racional es lineal, fijo y analítico. Pertenece a la esfera del intelecto, cuya función es diferenciar, medir y catalogar, y por ello tiende a ser fragmentado. El conocimiento intuitivo, por otra parte se basa en la experiencia directa y no intelectual de la realidad que surge durante un estado expansivo de la conciencia, tiende a ser sintetizante y holístico" (Capra, 1996: 41)

Capra señala que nuestra sociedad siempre ha favorecido al modelo racional, restándole importancia al modelo intuitivo. Esta preferencia, respaldada por el sistema patriarcal y reforzado por el predominio de la cultura sensata durante los últimos tres siglos, ha conducido a un profundo desequilibrio cultural que se halla en la base misma de nuestra crisis actual y que se expresa en el desequilibrio entre el pensamiento y el sentimiento, entre los valores y el comportamiento y entre las estructuras sociales y la política.

Capra brinda una lista de las asociaciones entre los dos tipos de pensamiento:

\section{Cuadro 1}

\begin{tabular}{|c|c|}
\hline YIN & YANG \\
\hline $\begin{array}{ll}- & \text { Femenino } \\
- & \text { Contractivo } \\
- & \text { Sensible } \\
- & \text { Insenservador } \\
- & \text { Sintetizo } \\
\end{array}$ & $\begin{array}{ll}\text { - } & \text { Masculino } \\
& \text { Expansivo } \\
& \text { Exigente } \\
\text { - Agresivo } \\
\text { - Racional } \\
\text { Analítico }\end{array}$ \\
\hline
\end{tabular}

\section{EL NUEVO PARADIGMA EDUCATIVO}

En la segunda mitad del siglo XX comienzan las nuevas visiones del pensamiento y una concepción diferente del proceso de enseñanza aprendizaje. La revolución la inicia la Gestalt y es continuada por autores como Rogers (1995). La Gestalt propone una visión holística y positiva del ser humano, que se enriquecerá con los valiosos aportes de la "Frizgestalt", basada en las teorías y la psicoterapia de F. Perls. 
Rogers, por su parte, denunciará la vulgar transferencia del conocimiento en las aulas, la ausencia de democracia y la concepción pasiva que se tiene de los estudiantes. Junto con otras teorías afines, se comienza a configurar el llamado paradigma humanista de la educación, cuyo fundamento es la concepción integral del ser humano, así como de la inteligencia en sus múltiples dimensiones.

A fines de la década del setenta el nuevo paradigma se fortalece y se emprende una crítica más agresiva al modelo racionalista, nutriéndose de lo que hoy se conoce como las teorías postracionalistas y postmodernas de la educación, tales como: el constructivismo, las neurociencias, la inteligencia emocional, entre otras.

La justa crítica al modelo racionalista desembocará en una suerte de raciovitalismo, tal como lo expresa Maffesoli (1997)

"El afecto, lo emocional, lo afectivo, pertenecientes todos al orden de la pasión, ya no están separados en un dominio aparte, ya no son únicamente explicables a partir de categorías psicológicas, sino que van a convertirse en palancas metodológicas útiles para la reflexión epistemológica, y son completamente operatorias para explicar los múltiples fenómenos sociales que, sin ello, continuarían siendo totalmente incomprensibles"(Maffesoli, 1997: 68)

La ruptura con el racionalismo se establece también en el método de análisis, mientras el racionalismo "juzga" y "etiqueta", el nuevo paradigma pretende comprender los fenómenos, las acciones y las representaciones humanas por lo que son, y no en función de lo que deberían ser. Esto significa que no hay una verdad única, general, aplicable en todas partes y en todos los tiempos, sino más bien una multiplicidad de valores que se relativizan unos a otros, se complementan, se matizan y se enfrentan. Esto es lo que Maffesoli denomina "pensamiento integrativo" y "razón sensible", capaces de asumir lo mejor del análisis moderno y lo que resulta pertinente del pensamiento analógico.

Paralelamente a la crítica y al cuestionamiento de las bases del racionalismo, el nuevo paradigma establece la pugna entre el individuo y el sujeto. Tendiendo a relegar al sujeto y reivindicando al individuo. Es importante señalar, que la idea del fin del sujeto es una constante en toda la tradición postmoderna, es así como lo expresa uno de sus mejores exponentes, Vattimo (1990):

"La sociedad ya no tiene unidad, de manera que ningún personaje, ninguna categoría social, ningún discurso posee el monopolio del sentido" (Vattimo, 1990: 36)

Otro autor, Guilles Lipovetsky, (1990) considerado una autoridad del pensamiento postmoderno, llama la atención acerca de la importancia del individuo:

"Los líderes intelectuales se extinguen, se eclipsa la autoridad de los maestros y estos dejan de ser los modelos preponderantes, en su lugar proliferan las influencias microscópicas y tiene lugar una superindividualización de los seres" (Lipovetsky, 1990: 311).

En otra obra, Lipovetsky (1998), señala que todas las esferas de la sociedad avanzan hacia un proceso de "personalización multifome".

Los postracionalistas prácticamente declaran la muerte del sujeto al poseer una visión inmediatista y reduccionista del hombre. Este pensamiento esta presente en muchos de los autores de la corriente, por ejemplo, así define Maturana (2000) a los seres humanos:

"Los seres humanos somos animales amorosos. El amor es una cosa muy simple, cotidiana, no es una virtud, es una condición relacional en la cual vivimos, que funda lo social y que es central en la vida humana. El conducirnos unos con otros en términos tales que el otro surge como legítimo otro en convivencia con uno, eso es el amor" (Maturana, 2000:30) 
En suma, sin pretender desconocer las justas críticas que se le hicieron al modelo racionalista desde la segunda mitad del siglo XX y que fueron reforzadas por las corrientes postmodernas. El nuevo paradigma deja sin resolver grandes dilemas; entre ellos: el equilibrio de lo racional y lo irracional en el proceso de enseñanza aprendizaje y en particular, la álgida relación entre individuo, sujeto y subjetividad.

A continuación se puede observar la oposición de los dos paradigmas:

\section{Cuadro 2}

\begin{tabular}{|c|c|}
\hline RACIONALISMO & POSTRACIONALISMO \\
\hline $\begin{array}{ll}\text { - } & \text { Razón } \\
\text { - } & \text { Explicativo/Analítico } \\
\text { - } & \text { Clasificador/Catalogador } \\
\text { - } & \text { Categorías Absolutas } \\
\text { - } & \text { Conocimiento lógico/Formal } \\
\text { - } & \text { Docente Autoritario/Represivo } \\
\text { - Estudiantes Pasivos/Receptores }\end{array}$ & $\begin{array}{ll}\text { - } & \text { Raciovitalismo } \\
\text { - Intuitivo/ Emocional } \\
\text { - } \text { Creatividad/Complejidad } \\
\text { - Categorías relativas/Múltiples } \\
\text { - Conocimiento Integral } \\
\text { - Docente Democrático } \\
\text { - Estudiantes Activos/ } \\
\text { Participantes }\end{array}$ \\
\hline
\end{tabular}

\section{LOS LIIMITES DEL PARADIGMA POSTRACIONALISTA}

Lo que ocurrió con la tradición gestáltica y las escuelas psicologistas que inauguraron el paradigma humanista de la educación en los últimos años, ha sido un tanto desalentador, los desarrollos que de ellas se hicieron han culminado en la crisis del pensamiento original de estas teorías. El desenlace ha llevado a un exceso de teoría especulativa volcada a la transpersonalidad, la mística, la religiosidad, el chamanismo, con el énfasis en las filosofías irracionales "underground", psicodelias, iluminismos, éxtasis y lógicas francamente narcisistas. Es así como se puede resumir lo que caracteriza buena parte de las visiones antimodernas y antiracionalistas.

Otras disciplinas han sido víctimas de la especulación, como el caso de las neurociencias, que se han convertido en una suerte de "tendencia mentalista", bajo el lema: "lo único que importa es la mente", no mejor suerte ha tenido el constructivismo radical, el cual supone un retorno a las teorías neokantianas de principios de siglo XX. Así mismo, es altamente cuestionable el efecto abiertamente domesticador de algunas teorías, como la del compromiso que pretende establecer Goleman (1995), entre el modelo educativo y el mercado, al promover la "implicación emocional" del trabajador con el capital. Por otro lado, todas estas corrientes han estado acompañadas de una inmensa "literatura de masas" que se ha popularizado y ha invadido los centros de enseñanza en todos los niveles.

Según G. Baremblitt (1997), se calcula entre 250 y 500 el número de estas corrientes consideradas terapéuticas, humanistas y "educativas", algunas de ellas son bastante conocidas, como por ejemplo: "Potencial Humano", "Bioenergética", "Terapias Guestálticas", "Psicologías Transpersonales y Holísticas", 
"Hipnosis", "Neurolingüistica", "Sistemas de Relajación", a las que pueden sumarse una gama muy amplia de planteos orientalistas o místico-religiosos presentados como psicoterapéuticos o de encuentro con dimensiones valiosas de la personalidad, y también "ciertas 'tecnologías' tales como las terapias por Cristales, por Colores, por 'Biorresonancia', por 'Pirámides', 'Florales', etc.

El resultado de todo esto es un reforzamiento del individualismo y la generación de una subjetividad extremadamente adaptativa y conservadora. Tal como lo expresa Béjar (1989):

“El psicologismo contemporáneo, afín al individualismo utilitario occidental, genera una sociedad vulnerable: sus ciudadanos aceptan, conformistas, un proceso de privatización que les hace cada vez más dependientes entre sí. Se crea así una ideología intimista que limita la experiencia al universo de la intersubjetividad" (Béjar, 1989: 12)

Paralelamente al individualismo se gesta una cultura del yo y una concepción personalizada y narcisista del éxito, que reduce la capacidad crítica del individuo, privilegiando en su lugar la capacidad adaptativa y un "yo claustrofóbico". Mediante las llamadas técnicas de autocontrol y otras estrategias se busca la anulación del papel social del individuo y una desmedulación del sujeto histórico.

Esta anulación del sujeto no conduce a otra cosa que a la autocomplacencia con los nuevos tiempos y con las condiciones materiales de vida, el cese de la participación en la vida pública y el abandono del deber social, dejándose los problemas sociales a su propia suerte y fomentándose un encierro acrítico y exclusivo en la esfera privada. Baremblitt señala que:

"Estas corrientes están destinadas a administrar los efectos de la anormalidad, la vulnerabilidad, el desvío, la desagregación, la desinserción, la marginalización, la clandestinidad, la reclusión y hasta la eliminación que el Sistema dominante induce a contingentes cada vez mayores de la población mundial... generalmente están dirigidas a los objetivos propios del individualismo, es decir, al desarrollo de la capacidad competitiva, a la auto-suficiencia, a la desculpabilización, al auto-control adaptacionista y exitista.." (Baremblitt, 1997: 19)

Paralelamente a ello, el divorcio absoluto que algunas tendencias pretenden del modelo racionalista conduce a los peligros que alerta Sartori (1998) en una de sus obras:

"Un hombre que pierde la capacidad de abstracción es no ipso, incapaz de racionalidad y es, por tanto un animal simbólico que ya no tiene capacidad para sostener y menos aún para alimentar el mundo construido por el homo sapiems" (Sartori,1998:146)

Sartori hace referencia a la sociedad comunicacional en la que estamos inmersos, a la fuerte irracionalidad que está presente en ella, o lo que en la tradición foucaultiana podría entenderse como "la sociedad del control". En estas sociedades se corre el peligro de desplazar la cultura escrita y la palabra por la de la imagen, o en otras palabras, de lo visible sobre lo inteligible. En el campo educativo, esto significa la conversión del niño en un "video niño" y por tanto, en un adulto sordo de por vida a los estímulos de la lectura y del saber transmitido por la cultura escrita.

Frente a tal panorama, se hace necesario deslindar el paradigma humanista de los excesos de irracionalismo y de individualismo y regresar a sus bases originales, reconstruyendo lo social y estableciendo un equilibrio en la relación individuo, sujeto y subjetividad.

A continuación se pueden observar las subjetividades contradictorias que se generan al oponer el individuo al sujeto. 
Cuadro 3

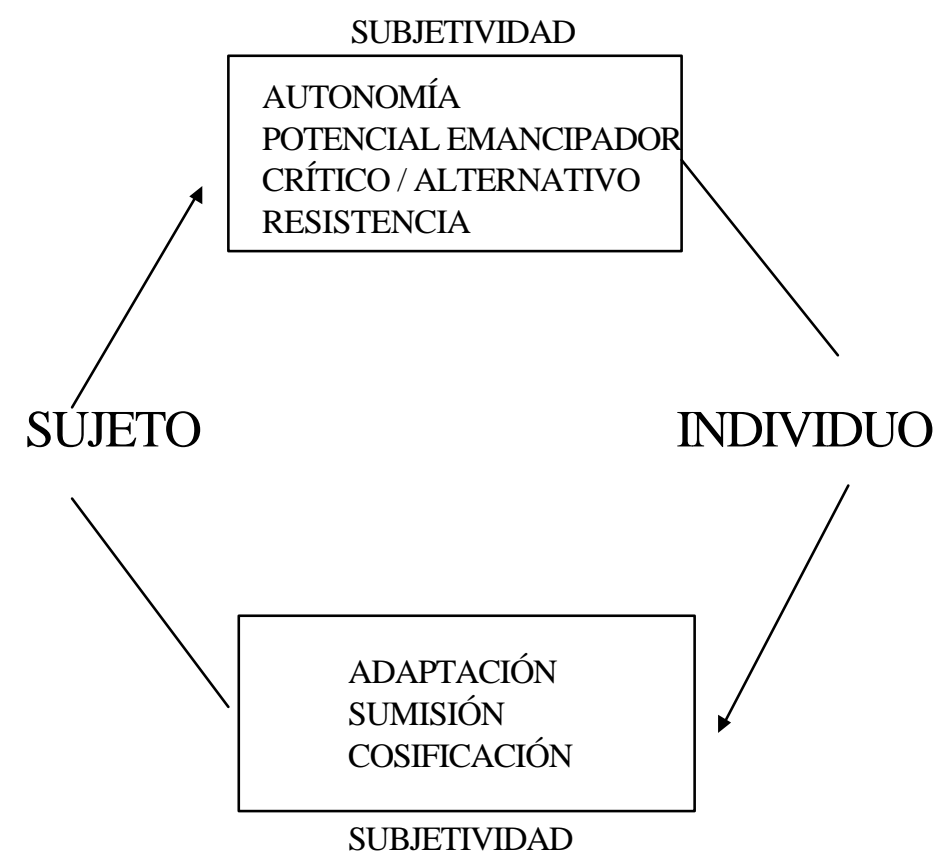

\section{HACIA UN MODELO EDUCATIVO HUMANISTA Y SOLIDARIO}

En primer lugar, es necesario reivindicar los postulados iniciales de las teorías psicológicas holistas y positivas del ser humano, que lo conciben como dueño de su destino, consciente y responsable de todas sus potencialidades.

En segundo lugar, resaltar la importancia de la relación que el hombre establece con su entorno natural y social, en este sentido vale destacar un aspecto extremadamente arrinconado por los enfoques postracionalistas y que consiste precisamente en reivindicar el papel del individuo como sujeto histórico. En la noción de sujeto encontramos el ingrediente activista y transformador, es decir, aquella en la que se desarrolla una actitud que busca transformar ese entorno y adecuarlo a las necesidades humanas. En las sociedades modernas, todo propósito que apunte a la transformación del entorno exige una conducta de lucha y esto supone la reivindicación de los colectivos organizados.

En tercer lugar, restablecer un racionalismo equilibrado y sin excesos que permita el conocimiento objetivo del entorno y romper con las conductas de pasividad y subordinación frente a él. Así mismo restablecer los valores de la fraternidad y la solidaridad.

Finalmente, junto a la recuperación de la conciencia racional y crítica se ha de estimular la capacidad utópica para prefigurar el futuro, esto significa alentar las propuestas y las alternativas para una sociedad postcapitalista.

\section{CONCLUSIONES}

Las teorías postracionalistas discuten las rigideces del modelo educativo y su incapacidad para captar múltiples aspectos de la inteligencia, así como los diversos aspectos implicados en el proceso de enseñanza aprendizaje. 
Inicialmente encontraremos la configuración de un paradigma alternativo al modelo racionalista basado en una concepción humanista de la educación, que se inspira y se sustenta en las visiones integradoras holísticas y positivas del ser humano. Este paradigma evolucionará hacia posturas de corte antiracional e individualista que lo hacen muy cuestionable en el campo de la educación. Lo cual hace necesario reivindicar alternativas diferentes a este paradigma basadas en un racionalismo equilibrado y en una concepción que sea a la vez humanista y solidaria.

Finalmente, aunque las críticas y los cuestionamientos de las teorías postracionalistas al modelo racionalista resulten acertadas y justas, éstas, han evolucionado hacia un pensamiento reaccionario, convirtiéndose en una suerte de "subcultura" que le hace juego a la fase actual del capitalismo y al pensamiento neoliberal. En definitiva, el postracionalismo termina por promover una cultura individualista y de automarginación que contribuye eficazmente a la estabilidad del sistema.

\section{BIBLIOGRAFÍA}

BAREMBLITT, Gregorio. (1997) "Por una nueva clínica para el poliverso 'Psy'", en Saúde Loucura. A clínica como ela é, Sao Paulo. Editora Hucitec.

BÉJAR, Helena. (1989). La cultura del yo. Madrid. Alianza editorial.

CAPRA, Fritjof. (1996). El punto crucial. Ciencia, sociedad y cultura naciente. Buenos Aires. Editorial Estaciones.

GoLEMAN,D. (1995). Inteligencia emocional. Buenos Aires. Vergara.

LIPOVETSKY, Guilles. (1998). La era del vacío. Ensayos sobre el individualismo contemporáneo. Barcelona. Anagrama.

LIPOVETSKY, Guilles. (1990). El imperio de lo efímero. La moda y su destino en las sociedades modernas. Barcelona. Anagrama.

MAFFESOL, Michel. (1997). Elogio de la razón sensible. Una visión intuitiva del mundo contemporáneo. Buenos Aires. Paidós.

MATURANA, Humberto. (2000). "Apuntes para una biología del amor" en Bioética. La calidad de vida en el siglo XXI. Bogotá. Ediciones El Bosque.

ROGERS, C. (1995). El camino del ser. Madrid. Kairos.

SARTORI, Giovanni. (1998). Homo videns. La sociedad teledirigida. Madrid. Taurus.

VATTIMO, Gianni. (1990). La sociedad transparente. Barcelona. Paidós. 


\title{
Contactar
}

Revista lberoamericana de Educación

\author{
Principal OEI
}

